\title{
Epithelial-mesenchymal axis in head and neck cancer cell lines
}

\author{
Arutha Kulasinghe ${ }^{1}$, Chris Perry ${ }^{2}$, Glen M. Boyle ${ }^{3}$, Ken O'Byrne ${ }^{4}$, Anthony Davies ${ }^{4}$, Lidija Jovanovic ${ }^{5}$, Colleen \\ Nelson $^{5}$, Chamindie Punyadeera*1 \\ ${ }^{1}$ School of Biomedical Sciences, Institute of Health and Biomedical Innovation, Queensland University of Technology, Kelvin \\ Grove, QLD, Australia \\ ${ }^{2}$ Department of Otolaryngology, Princess Alexandra Hospital, Woolloongabba, QLD, Australia \\ ${ }^{3}$ QIMR Berghofer Medical Research Institute, Herston, Brisbane, QLD, Australia \\ ${ }^{4}$ Translational Cell Imaging Queensland, Institute of Health and Biomedical Innovation, Queensland University of Technology, \\ Translational Research Institute Brisbane, Australia \\ ${ }^{5}$ Australian Prostate Cancer Research Centre - Queensland, Institute of Health and Biomedical Innovation, Queensland \\ University of Technology, Princess Alexandra Hospital, Translational Research Institute Brisbane, Australia
}

Received: October 20, 2015

DOI: $10.5430 /$ jst.v6n1p28
Accepted: December 2, $2015 \quad$ Online Published: December 14, 2015

URL: http://dx.doi.org/10.5430/jst.v6n1p28

\begin{abstract}
Objectives: Head and neck squamous cell carcinoma (HNSCC) is a heterogeneous tumour type which necessitates multiple in vitro models to attain an appreciation of its multiple subtypes. The phenomenon of epithelial-mesenchymal transition (EMT) is important to the development of a metastatic cancer cell phenotype being relevant to the ability of cancer cells to intravasate into vasculature and to invade tissues. The role of EMT in human papilloma virus (HPV) positive HNSCC is not well understood. This paper aims to characterize seven HNSCC cell lines (FaDu, SCC-25, SCC-15, CAL27, RPMI2650) including two new HPV-16 positive HNSCC cell lines (UD-SCC2, 93-VU-147T) for their epithelial and mesenchymal properties.
\end{abstract}

Materials and methods: A panel of HNSCC cell lines from multiple head and neck anatomical sites were profiled for basal expression of epithelial and mesenchymal characteristics at mRNA, protein and functional levels (proliferative, migratory and invasive properties). Furthermore, 3D spheroid forming capabilities were investigated.

Results: We found that the HPV-16 positive cell line, in particular UD-SCC2 demonstrated a more invasive and mesenchymal phenotype at the molecular and functional levels suggesting HPV infection may mediate some of these cellular properties. Moreover, HPV-negative cell lines were not strictly epithelial presenting with a dynamic range of expression.

Conclusions: This study presents the molecular and phenotypic diversity of HNSCC cell lines. It highlights the need for more studies in this field and a scoring system where HNSCC cell lines are ranked according to their respective epithelial and mesenchymal nature. This data will be useful to anyone modelling HNSCC behaviour, providing a molecular context which will enable them to decipher cell phenotypes and to develop therapies which block EMT progression.

Key Words: Head and neck cancer, Head and neck squamous cell carcinoma, Epithelial-mesenchymal transition, Human papillomavirus

*Correspondence: Chamindie Punyadeera; Email: chamindie.punyadeera@qut.edu.au; Address: School of Biomedical Sciences, Institute of Health and Biomedical Innovation, Queensland University of Technology, Kelvin Grove, QLD, Australia. 


\section{INTRODUCTION}

Head and neck squamous cell carcinoma (HNSCC) is globally the sixth highest cause of cancer mortality. ${ }^{[1]}$ Worldwide it causes an estimated 600,000 cases per annum ${ }^{[1]}$ and has five-year patient survival statistics between $40 \%-50 \%$ with little improvement in the past 40 years. ${ }^{[2,3]}$ It is a heterogeneous disease primarily affecting the oral cavity, salivary glands, oropharynx, hypopharynx, and larynx. Risk factors for HNSCC include alcohol and tobacco consumption (independently as well as synergistically), betel nut chewing and the use of dentures. ${ }^{[4]}$ Viral oncogenic human papillomavirus (HPV) is an aetiological factor. The profile of HPV associated HNSCC appears to be genetically, molecularly and clinically different from HPV-negative HNSCC. ${ }^{[5-8]}$ There are high risk subtypes such as HPV-16 and HPV-18 found in the oropharynx. The different subtypes of head and neck cancer provide opportunity for the development of novel therapeutic agents and warrant the need for a panel of model systems for their investigation in vitro.

As with other tumour types, HNSCC cell lines provide an invaluable in vitro model system to investigate tumour growth, development and metastasis, and therefore have applications to the pre-clinical screening of potential drug targets. ${ }^{[9]}$ Knowledge of the molecular alterations that exist within established HNSCC cell lines provides insight into the tumour phenotypes they represent. One crucial factor in the clinical manifestation of HNSCC that relates to the progressive attainment of molecular aberrations is the pre-existence of HPV infection, evidence of which can be readily demonstrated in some, but not all, HNSCC derived cell lines. Recent investigations by The Cancer Genome Atlas (TCGA) Research Network discovered that HPV-associated tumours have specific gene alterations in FGFR3 and mutations in PIK3CA. Moreover, the EGFR gene is frequently altered in HPV-negative tumours whereas in HPV-positive tumours it is rarely found to be altered. ${ }^{[10]}$ These insights provide crucial information for the development of therapies. In the present study, in vitro model systems have been used to investigate potential correlation between HPV pre-existence in cell lines with phenotypic and genotypic determinants of Epithelial-mesenchymal transition (EMT) .

EMT describes the development of a motile mesenchymallike cell phenotype by formerly non-motile epithelial cells. It occurs during embryonic development, wound healing, fibrosis and cancer. ${ }^{[11]}$ EMT facilitates migration and invasion in most solid tumours, leading to both micro- and macro- metastasis and may promote cancer cell resistance to therapies through reduced susceptibility to anoikis and apoptosis. ${ }^{[12]}$ The molecular and macromolecular changes that underlie loss of epithelial cell-cell adhesion, loss of Published by Sciedu Press apical-basal polarity and loss of epithelial anchorage to the basement membrane have been described for numerous cancers including those of the head and neck. ${ }^{[13]}$ Known EMT biomarkers in HNSCC include cell surface proteins (E-cadherin, N-cadherin) ${ }^{[14-16]}$ cytoskeleton proteins $(\beta$ catenin, Vimentin), ${ }^{[14,17,18]}$ extracellular matrix proteins (Fibronectin) ${ }^{[19,20]}$ and transcription factors (Snail1). ${ }^{[21,22]}$ The process of EMT has been associated with the gain of stem cell-like properties, ${ }^{[23]}$ with numerous cancer stem cell markers described for head and neck cancers including: CD133, CD44, CD24, ALDH1, ABCG2 and Bmi1. ${ }^{[24-27]}$ To investigate the correlation between the phenotypic and genotypic characteristics of HNSCC cell lines and their pre-existence of HPV, our hypothesis was that HPV-16 positive cell lines would present with a more mesenchymal and invasive cell type. The aim of this study was to assess a panel of established HNSCC cell lines originating from a spectrum of anatomical sites and histologies that could be used for studying the molecular, and phenotypic diversity of head and neck cancer. We have characterised seven HNSCC cell lines on their ability to proliferate, invade and migrate as well as their expression of EMT markers.

\section{MATERIAls AND METHODS}

\subsection{Cell culture and reagents}

Three HNSCC cell lines $\left[\mathrm{FaDu}\left(\mathrm{ATCC}{ }^{\mathrm{R}} \mathrm{HTB} 43^{T M}\right.\right.$ ), CAL27 (ATCC ${ }^{\circledR}$ CRL $2095^{\mathrm{TM}}$ ), RPMI2650 (ATCC ${ }^{\mathrm{R}}$ CCL$\left.30^{T M}\right)$ ] (Passage range 6-12) were from the American Type Culture Collection (ATCC ${ }^{T M}$ ). Two HNSCC HPV-16 positive cell lines; 93-VU-147T and UD-SCC2 were gifted to us. 93-VU-147T (Passage range 46-51) from Dr Johan de Winter (VU Medical Center, Amsterdam, Netherlands), UD-SCC2 (Passage range 16-20) from Dr Thomas Hoffman (Uniklinik). Two cell lines were a generous gift from Associate Prof. Nick Saunders (University of Queensland Diamantina Institute); SCC15 (ATCC ${ }^{\circledR}$ CRL-1623 ${ }^{T M}$ ) (Passage range 4-8) and SCC25 (ATCC ${ }^{\circledR}$ CRL-1628 ${ }^{T M}$ ) (Passage range 5-9). To avoid the influence of culture media, all culture media conditions were standardized to RPMI-1640-Glutamax (Life Technologies, Inc), supplemented with $10 \%$ foetal bovine serum (Life Technologies, Inc) and 1\% Penicillin-Streptomycin (Life Technologies, Inc) at $37^{\circ} \mathrm{C}$ and $5 \% \mathrm{CO}_{2}$ in $75 \mathrm{~cm}^{2}$ tissue culture flasks.

\subsection{STR profiling}

Cell line identity was routinely checked by Short Tandom Repeat (STR) profiling with the StemElite ${ }^{T M}$ ID System (Promega) according to the manufacturer's instructions. Cell lines were also checked for mycoplasma infection by Hoechst staining ${ }^{[28]}$ and PCR, and were always negative. 


\subsection{RNA isolation}

Cells were cultured to $80 \%$ confluence and then scraped in $800 \mu \mathrm{l}$ of QIAzol Lysis Reagent (Qiagen, Germany). Total RNA isolation was performed using an in-house developed protocol. ${ }^{[29]}$ In brief, the samples were vortexed for $5 \mathrm{~min}$ utes at room temperature, to which $200 \mu \mathrm{l}$ of Chloroform was added to each $1.5 \mathrm{ml}$ Eppendorf tube and vortexed vigorously. The samples were centrifuged at $10,000 \times \mathrm{g}$ for 10 minutes at $4^{\circ} \mathrm{C}$. The upper layer was then transferred to a new Eppendorf tube to which another $200 \mu \mathrm{l}$ of Chloroform was added, vortexed and centrifuged (as above). The upper aqueous layer was transferred to a new Eppendorf tube and an equal volume of isopropyl alcohol was added and vortex mixed and stored overnight at $-20^{\circ} \mathrm{C}$. The following day, the samples were centrifuged at $10,000 \times \mathrm{g}$ for 20 minutes at $4^{\circ} \mathrm{C}$ and the supernatant removed and discarded. The pellet was air dried and resuspended in $20 \mu \mathrm{l}$ of RNase-free water and stored at $-80^{\circ} \mathrm{C}$. The quality and quantity of isolated RNA was measured with a NanoDrop ND-1000 spectrophotometer (Thermo Scientific, USA). The RNA isolated with the QIAzol method was tested for RNA integrity with a 2100 Bioanalyzer (Agilent Technologies, USA).

\section{4 cDNA synthesis and real-time PCR (qPCR)}

One $\mu \mathrm{g}$ of RNA was treated with 2 units of DNase (New England Biolabs) according to manufacturer's instructions to remove genomic DNA. The RNA was then reverse transcribed to cDNA with iScript cDNA Synthesis Kit (Bio-Rad, USA) according to the manufacturer's instructions. SYBR Green real-time quantitative PCR was performed on the Applied Biosystems ${ }^{\circledR}$ ViiA $^{T M}$ Real-Time PCR system. Primer pairs were added to $50 \mathrm{ng}$ of cDNA to a final concentration of $0.4 \mu \mathrm{M}$ each in a final volume of $10 \mu \mathrm{l}$. All reactions were performed in duplicate in a 384-well plate (Life Technologies, USA). PCR amplification was performed following an initial 10 minute denaturation step at $95^{\circ} \mathrm{C}$ with $40 \mathrm{cy}$ cles at $95^{\circ} \mathrm{C}$ for 15 seconds and $60^{\circ} \mathrm{C}$ for 60 seconds. Melt curve was included in each run. Quantitative gene expression was performed for EpCAM (EGP-40), E-Cadherin (CDH1), Cytokeratins (KRT5, KRT18, KRT19), Vimentin (VIM), N-Cadherin (CDH2), Fibronectin (FN1), SNAI1, SNAI2, EGFR, CD44, p21 (CDKN1A) and p53 (TP53). Data was normalized to the internal control, GAPDH to obtain (delta $\mathrm{Ct}$ )/ relative expression, centred and standardized.

\subsection{Protein extraction and western blot}

Cells were grown in 6-well plates to $50 \%-70 \%$ confluency, washed with ice cold PBS and lysed in RIPA buffer $(50 \mathrm{mM}$ Tris $\mathrm{HCl}, 150 \mathrm{mM} \mathrm{NaCl}, 0.1 \%$ Trition X-100, 0.5\% sodium deoxycholate, $0.1 \%$ SDS, $1 \mathrm{mM}$ EDTA) with freshly added protease inhibitor cocktails. Cell lysates were sonicated four times for 30 seconds with 30 second cooling intervals on ice, followed by centrifugation at $13,000 \times \mathrm{g}$ for 15 minutes at $4^{\circ} \mathrm{C}$ to obtain the supernatant. Protein concentrations were quantified using the BCA protein assay kit (Pierce Biotechnology, Illinois, USA) as per manufacturer's instructions.

Equal amounts of protein $(25 \mu \mathrm{g})$ were combined with $5 \times$ loading buffer containing sample reducing agent and denatured at $95^{\circ} \mathrm{C}$ for 5 minutes. Protein samples were loaded into a 10 well $7.5 \%$ Mini-Protean ${ }^{\circledR}$ TGX Stain-Free ${ }^{T M}$ Gel and electrophoresed at $150 \mathrm{~V}$ for 60 minutes in Running Buffer. Protein standards were run alongside the samples for size determination. Following electrophoresis, proteins were transferred onto a PVDF membrane (Millipore) using standard protein transfer apparatus. For immunoblotting, membranes were blocked in TBST containing 3\% skim milk for 1 hour at room temperature, followed by incubation with primary antibodies diluted in blocking solution overnight at $4^{\circ} \mathrm{C}$ with rotation. E-Cadherin $(1: 2,500)$, EpCAM (1:1,000), N-cadherin $(1: 1,000)$, Vimentin $(1: 1,000)$, Fibronectin (1:1,000), Zeb1 (1:1,000), EGFR (1:5,000), pEGFR (1:8,000). After overnight incubation, the membranes were washed three times with TBST ( 9 minutes/wash) and then incubated with horseradish-conjugated secondary antibodies for 1 hour at room temperature, followed by 3 washes in TBST. To develop luminescence, membranes were soaked in Chemoluminescence Luminol reagent (Thermo Scientific Pierce, Illinois, USA) for seven minutes. Protein bands were visualized on the ChemiDoc ${ }^{T M}$ MP imaging system. Positive and negative controls were used for both epithelial and mesenchymal cell types.

\subsection{Immunofluorescent staining}

Cytospins (Cytospin ${ }^{T M} 4$ Cytocentrifuge, USA) were prepared using aliquots of 500 cells/slide by cytocentrifugation at $1,000 \times \mathrm{g}$ for $5 \mathrm{~min}$. The slides were air dried and fixed with 4\% PFA for 15 min and stained with antihuman EGFR Antibody AY13 (Biolegend, USA) for $2 \mathrm{~h}$ at room temperature. Subsequently, slides were stained with the DAPI for nuclear staining. ProLong ${ }^{\mathrm{A}}$ Gold Antifade mountant (Stephens Scientific) was used to prevent photobleaching and for the preservation of the fluorescent labelled molecules for long term storage. Slides were analysed under an Olympus IX73 epifluorescence microscope in the following channels: DAPI, FITC/GFP. EGFR staining was detected on the GFP/FITC channel and B-Cell lymphoma cell line served as an internal negative control.

\subsection{HAPPY CELL ${ }^{\circledR}$ protocol}

Cells were washed twice in RPMI 1640-Glutamax (Life Technologies, Inc) post trypsinisation and spun down at $1,000 \times$ 
$\mathrm{g}$ for 5 mins to obtain a cell pellet. After discarding the supernatant, the cell pellet was resuspended in pre-warmed $1 \times$ Happy Cell ${ }^{\circledR}$ (Biocroí Ltd., Dublin, Ireland) media at a density of 100,000 cells/ml. Optimal cell seeding densities were found by titrating cells from 10,000-1,000 cells/100 $\mu \mathrm{l} /$ well into 96F-well Spheroid plates (Thermo Scientific, USA) and 96 well Corning ${ }^{\circledR}$ Spheroid Microplates and incubated for 72 hours at $37^{\circ} \mathrm{C}$ and $5 \% \mathrm{CO}_{2}$. To perform spheroid staining, an inactivation buffer was used which collapsed the matrix holding the spheroids and incubated for 1 hour at $37^{\circ} \mathrm{C}$ and $5 \% \mathrm{CO}_{2}$. The spheroids settled to the bottom after where the immunofluorescent protocol was used for staining.

\subsection{Cell proliferation}

To determine cell proliferation, the cell lines were seeded in 12 replicates at 2,500 cells/well in a 96-well flat bottomed plate (Nunclon TC, USA Scientific) and visualized using a real-time cell imaging system (IncuCyte ${ }^{T M}$ live-cell ESSEN BioScience Inc, Michigan, USA) and were imaged every 2 hours to monitor the confluence. Percentage confluence were monitored using the high definition automated imaging system IncuCyte (Essen Bioscience, Germany), following manufacturer's protocol. The data were analysed using anal- ysis of variance (ANOVA) and displayed as mean \pm standard deviation.

\subsection{Cell migration}

Cell migration of the 7 cell lines was followed using a realtime cell imaging system, IncuCyte, to perform a scratch wound healing migration assay. Cells are imaged inside a standard incubator under optimal physiological conditions for the entire duration of the experiment. In brief, using 96-well ImageLock cell culture plates (Essen Bioscience Inc, Michigan, USA), seven HNSCC cell lines were plated at $4 \times 10^{4}$ cells/well overnight in a standard $\mathrm{CO}_{2}$ incubator to achieve $100 \%$ confluence. The next day, cells were pre-treated with Mitomycin C (10 $\mu \mathrm{g} / 100 \mu \mathrm{l})$ for 2 hours, media replaced and then a uniform and precise scratch was made using a 96-pin WoundMaker (Essen Bioscience Inc, Michigan, USA). The wells were washed with PBS (Life Technologies, Inc) to remove any debris and topped up with $100 \mu \mathrm{l}$ of culture media. The assay plates were equilibrated within the IncuCyte then migration was monitored every 2 hours. Data was analysed using the integrated metrics; relative wound density, wound confluence and wound closure rates.
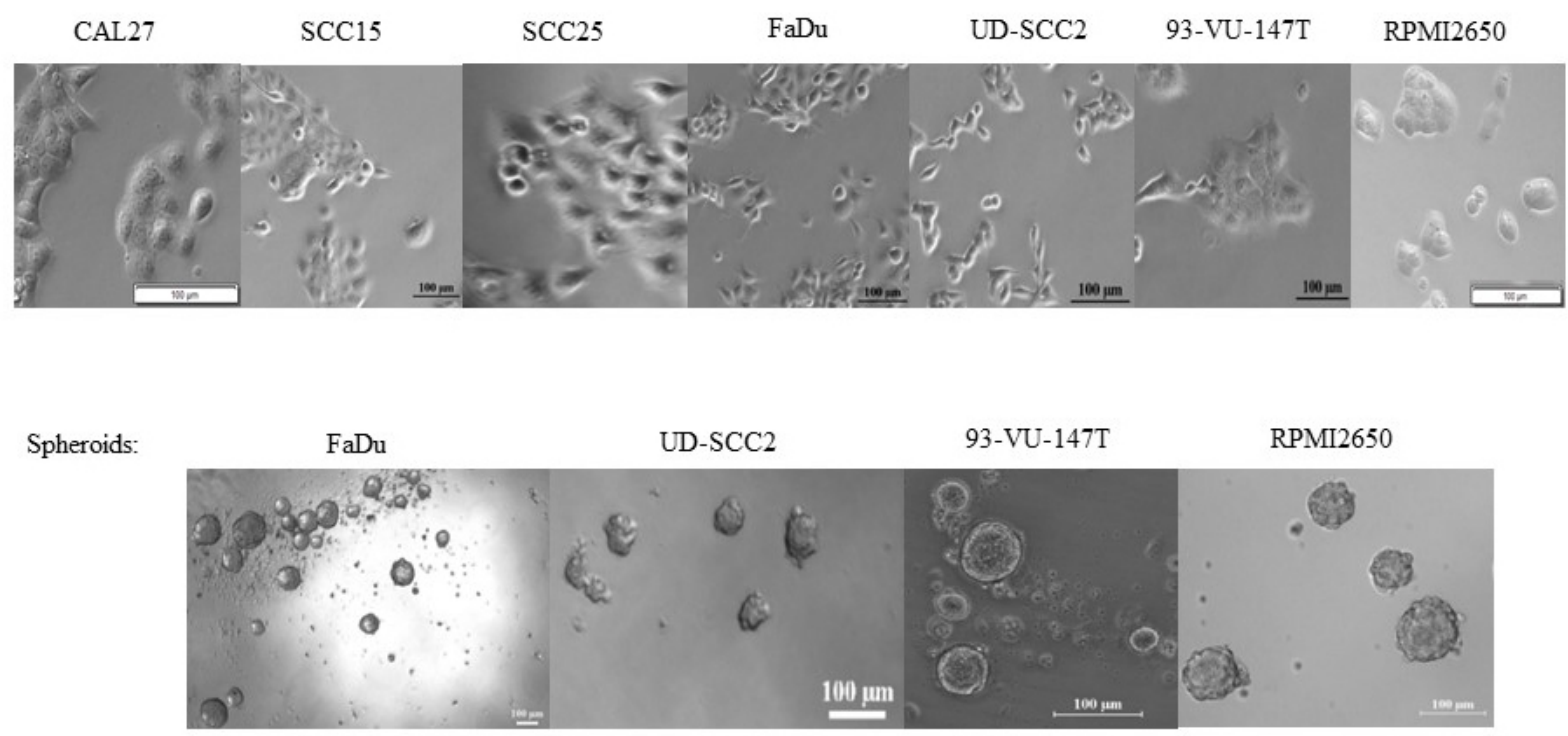

Figure 1. Imaging of head and neck squamous cell carcinoma in $2 \mathrm{D}$ and $3 \mathrm{D}$ tumour spheroids. Bright field microscopy images exhibit the epithelial phenotype of the cell lines $(\times 10)$. Most cell lines displayed an epithelial morphology consistent with a typical cobble-stone phenotype. The spheroids are a representation of the cell lines grown in a $3 D$ culture media $\left(\right.$ Happy Cell $\left.{ }^{\circledR}\right)$. The scale bar corresponds to $100 \mu \mathrm{m}$. Imaged at $\times 40$ Olympus IX73 inverted Microscope.

\subsection{Cell invasion}

Invasion assay was broadly similar to the migration assay, however, there was a pre-coated layer of growth factor reduced matrigel $(100 \mu \mathrm{g} / \mathrm{ml})$ (BD Biosciences, France) to which $4 \times 10^{4}$ cells were seeded and incubated overnight at $37^{\circ} \mathrm{C}, 5 \% \mathrm{CO}_{2}$. The following day, the WoundMaker

Published by Sciedu Press
(Essen Bioscience Inc, USA) was used to make a scratch. A few washes with culture media removed any debris, $50 \mu 1$ of Matrigel (BD Biosciences, France) at $1 \mathrm{mg} / \mathrm{ml}$ was added to each well. The assay plate was placed in the incubator for an hour to allow the Matrigel to solidify before $150 \mu \mathrm{l}$ 
of culture media was added to each well. Assay plates were then equilibrated within the IncuCyte for 15 minutes before the first scan. Relative wound density was used to report the data.

\section{RESULTS}

We wished to assess 7 HNSCC cell lines, including 2 HPV16 positive, for markers or characteristics of epithelial origin. Figure 1 presents the imaging of the 7 cell lines. The varying morphology was evident across the cell lines with FaDu pref-
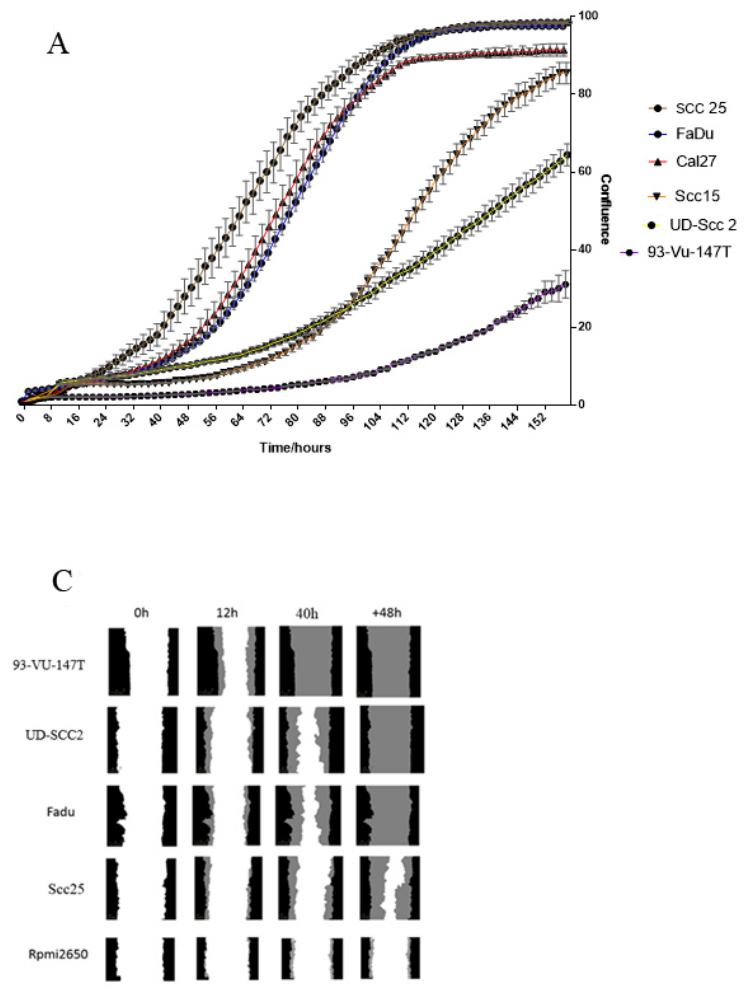

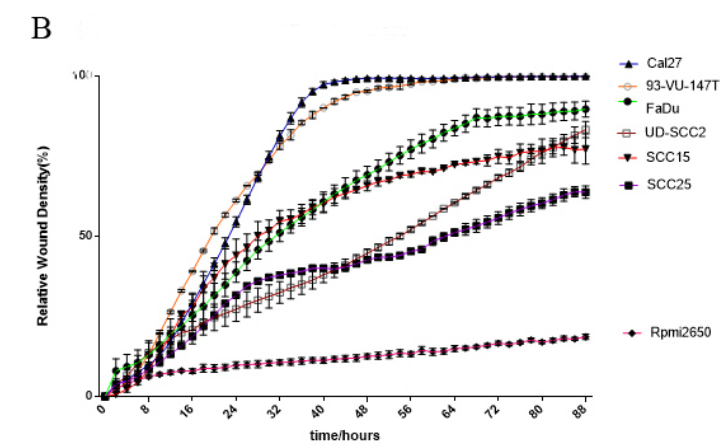

erentially growing in close groupings, whereas RPMI2650 more sparse and growing in isolated colonies. The HPV-16 positive cell lines also varied in morphology and proliferation. The HPV-16 positive cell lines, UD-SCC2 and 93-VU147T had the slowest proliferative rates (see Figure 2A) and 93-VU-147T formed web like structures between colonies over time and as the confluence increased with more interactions between colonies. The spheroids were grown in Happy Cell ${ }^{\mathrm{R}}$ for 5 days prior to imaging.

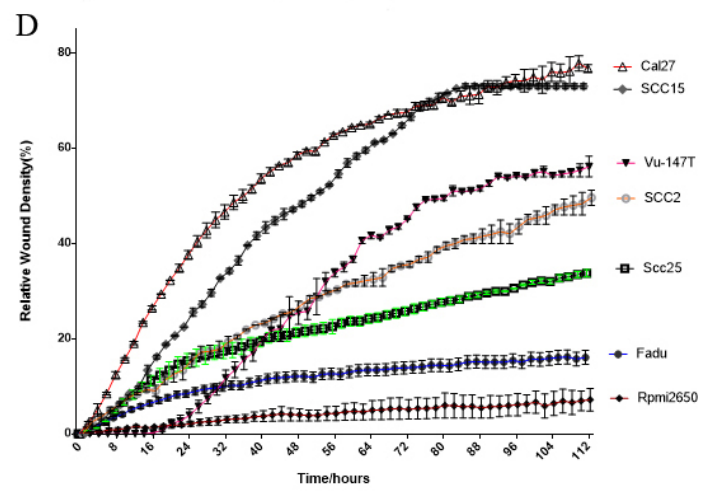

Figure 2. (A) The cell proliferation assay. Graph showing the cell proliferation for the 7 cell lines plotted over time. (B) The cell migration assay. Graph showing the migration of the 7 cell lines through media. (C) The cell migration assay depicted as a phase contrast image. The initial wound "mask" generated with the analysis algorithm is overlaid (grey) and defines the wound boundaries at 0 hours (Black). (D) The invasion Assay. Graph showing the invasion of the 7 cell lines through 3D-Matrigel after a scratch wound has been made. Imaged on the IncuCyteTM live-cell imager. HPV-16 positive cell lines: 93-VU-147T, UD-SCC2. HPV-negative cell lines: FaDu, SCC25, SCC15, CAL27, RPMI2650.

The proliferative rates are shown in Figure 2A where SCC25 and $\mathrm{FaDu}$ have the fastest growth rate/doubling time where it reaches $100 \%$ confluence in under 120 hours whereas the HPV-16 positive cell lines; 93-VU-147T and UD-SCC2 have the slowest growth rates and do not even reach $50 \%$ confluence in 156 hours. SCC25, human fibroblast (Wmpy.1), RPMI2650 and FaDu had similar proliferative rates.

The migratory rates were highest in CAL27 and 93-VU-147T (see Figure 2B \& 2C), where the scratch wound had closed within 48 hours. FaDu, SCC15 and UD-SCC2 migrated at a slightly lower migratory rate, however, longer than 48 hours for the scratch wounds to close. RPMI2650 has the slowest migratory rate.

CAL27 and SCC15 were observed to be highly invasive through Matrigel with approximately $80 \%$ of the scratch wound closed in the 3D matrix (see Figure 2D). The HPV-16 positive cell lines (93-VU-147T and UD-SCC2) had similar invasive rates with approximately $50 \%$ of the scratch wound 
closed in the observed time and higher invasive profiles than SCC25, FaDu and RPMI2650. SCC25 closed approximately $35 \%$ of the scratch wound whereas FaDu and RPMI2650 were well below $20 \%$ even after 100 hours.

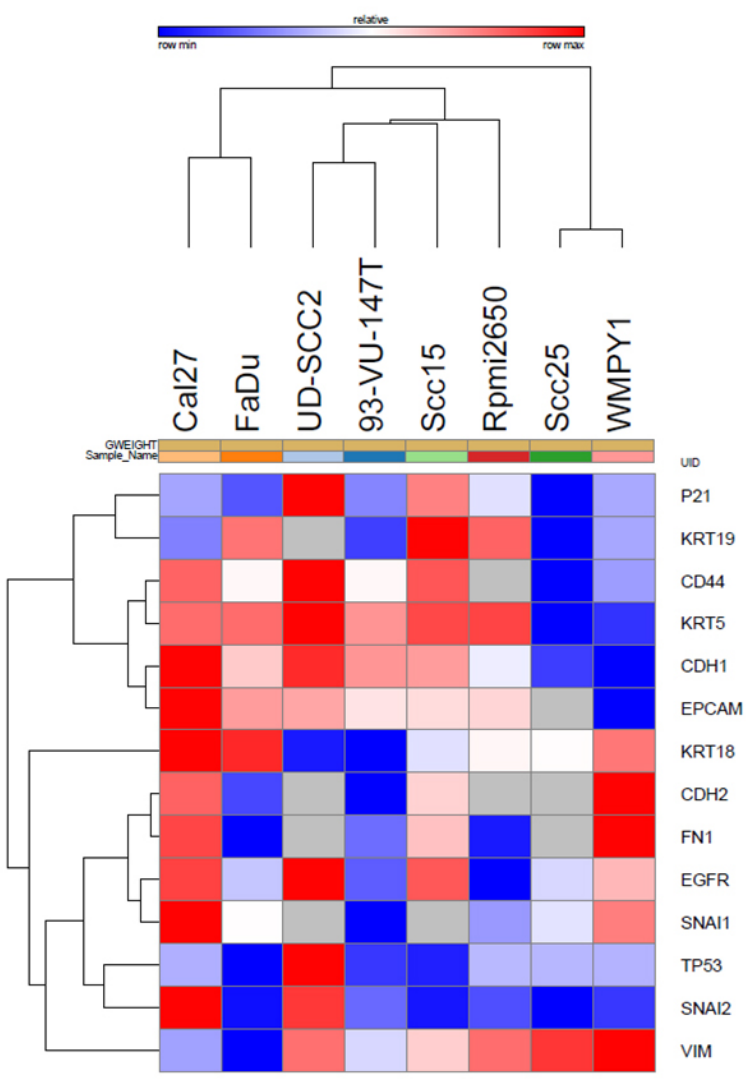

Figure 3. Heat Map presenting the gene expression data for a range of epithelial and mesenchymal markers. Positive control for mesenchymal markers: Wmpyl (Human Fibroblast) Grey blocks indicate that data is not available. Synonyms: $C D H 2=N$-cadherin $; C D H 1=E$-cadherin, $V I M=$ Vimentin, $K R T=$ Cytokeratin, $F N 1=$ Fibronectin .

UD-SCC2 and 93-VU-147T, CAL27 and FaDu, SCC25 and WMPY1 have similar associations (see Figure 3 ) at the transcriptional level. UD-SCC2, SCC25 and RPMI2650 at the mRNA level, appear to have a more mesenchymal nature to them by expression of the mesenchymal marker, Vimentin. The epithelial markers (EpCAM, E-cadherin) and cytokeratin (KRT5) are similarly expressed for CAL27, FaDu, UDSCC2, 93-VU-147T and SCC15 whereas SCC25 shows weak to no mRNA expression for these epithelial markers. SCC25 and WMPY1 have similar expression profiles. Human fibroblast cell line (WMPY1), a mesenchymal cell line was included for comparative purposes.

E-cadherin is expressed in most of the cell lines except for lower expression for UD-SCC2 and RPMI2650 (see Figure 4A). E-cadherin and N-cadherin appear to express sim- ilar protein expression across the cell lines. RPMI2650 lacks expression for either E-cadherin or N-cadherin. Vimentin expression is high for SCC25 and found in UD-SCC2 and RPMI2650 consistent with the mesenchymal cell line WMPY1.

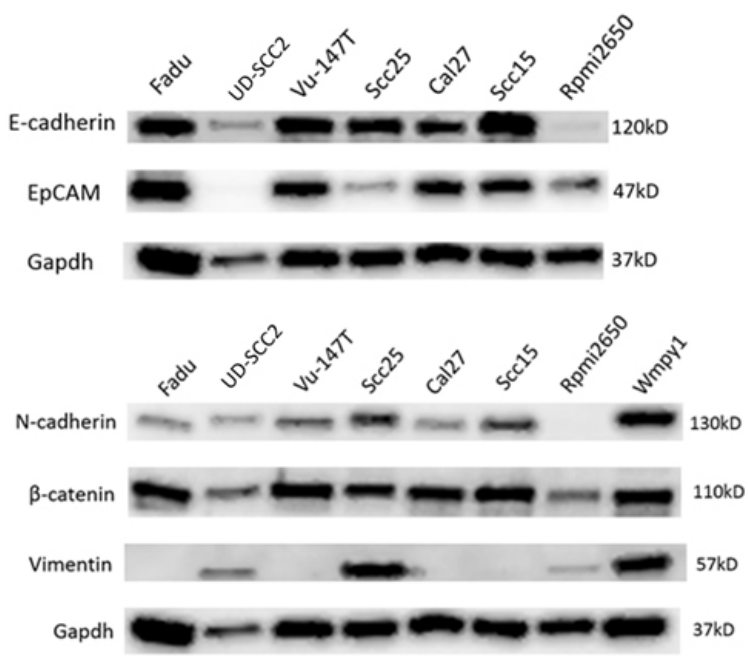

A

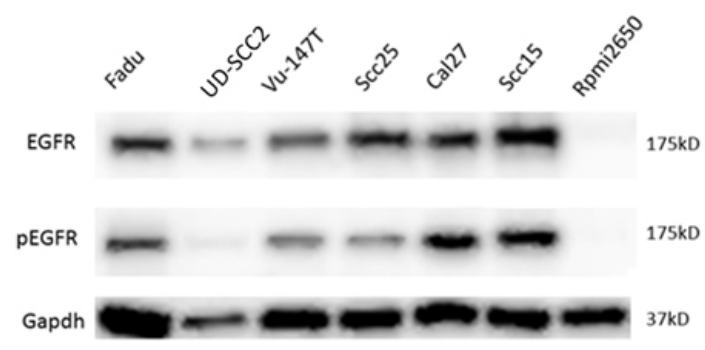

$\mathrm{B}$

Figure 4. (A) Protein expression of the epithelial and mesenchymal markers. Epithelial (E-cadherin, EpCAM); Mesenchymal (N-cadherin, Vimentin). (B) Protein expression of EGFR and phospho-EGFR. Molecular weight indicated on the right.

EGFR and pEGFR was found across all the cell lines except for RPMI2650 and UD-SCC2 (see Figure 4B). For RPMI2650, EGFR nor the activated phosphorylated form pEGFR was found. For UD-SCC2, weak EGFR expression was found and even weaker pEGFR. The western data is consistent with the gene expression.

FaDu and SCC25 showed strong surface expression of EGFR in comparison to RPMI2650 which showed weak EGFR expression (see Figure 5A). The lack of EGFR expression for RPMI2650 was consistent with mRNA and protein expression as seen in Figures 3 and $4 \mathrm{~B}$.

FaDu spheroids stained positively for EGFR, pan-cytokeratin and DAPI whereas RPMI2650 only stained positive for pan- 
cytokeratin and DAPI (see Figure 5B). This was consistent with the gene and protein expression data. The DAPI staining shows the multi-nucleated spheroid.

Figure 5C presents a visual depiction of the HPV-16 positive

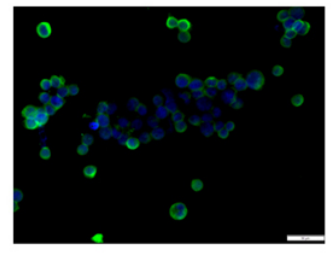

Fadu

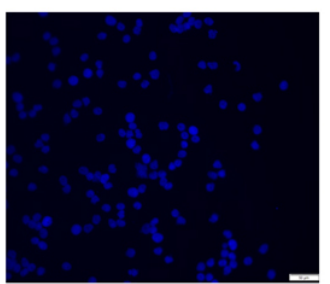

Rpmi2650

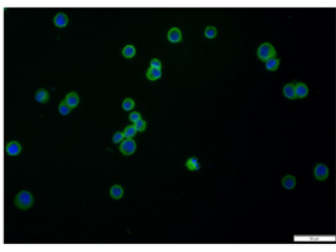

$\operatorname{scc} 25$

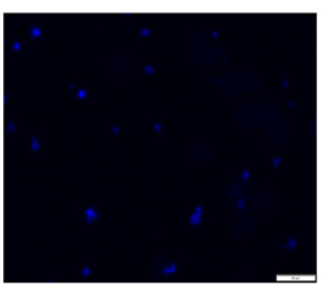

B Cell Lymphoma Mano

A
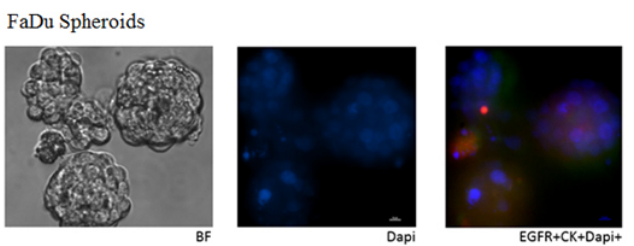

RPMI2650 Spheroids
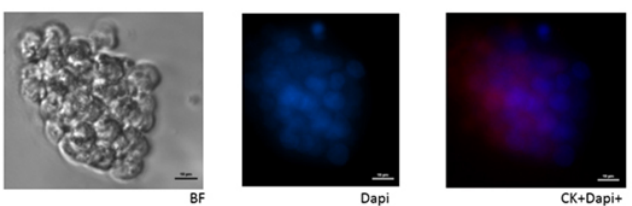

cell line, UD-SCC2 as to its epithelial and mesenchymal nature by co-staining for EGFR, Cytokeratin and Vimentin. The co-expression of both epithelial (cytokeratin, EGFR) and mesenchymal (Vimentin) markers is present.

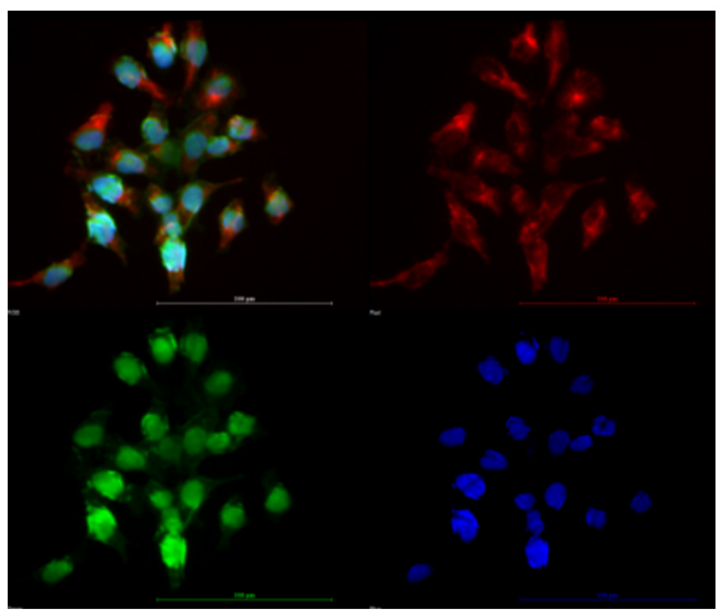

B

Figure 5. (A) EGFR Immunofluorescent staining performed on cell spins of FaDu, SCC25 and RPMI2650. Negative control: B Cell Lymphoma Mano. Nuclear stain Dapi (blue); Membrane bound EGFR (Green). White scale bar represents $50 \mu \mathrm{m}$. (B) Spheroids grown in 3D culture (Happy Cell $\left.{ }^{\circledR}\right)$. Stained for Dapi (blue), EGFR (green), Pan Cytokeratin (Red). White scale bar represents $10 \mu \mathrm{m}$. (C) Immunofluorescent staining of UD-SCC2 showing co-expression of epithelial and mesenchymal markers. Performed on cover slips of UD-SCC2 showing in the top left (Composite image-Vimentin, EGFR, DAPI), top right (Vimentin-Red), Middle Left (EGFR-Green) and Middle Right (DAPI-Blue) and Bottom Left (Cytokeratin-Orange) Scale bar represents $100 \mu \mathrm{m}$. Imaged on Olympus IX73 inverted Microscope.

\section{Discussion}

When developing novel therapeutic targets to treat HPV-16 positive and HPV negative HNSCC patients, it is paramount to understand the biological processes involved in tumour cells dissemination through the body, invasive capacity and metastasis. This warrant well characterised in vitro cell culture model systems to study drug effects in a preclinical setting. A large number of studies have demonstrated the role of EMT in tumorigenesis. ${ }^{[10,27,30,31]}$ However, there is a lack of data pertaining to EMT characteristics in HNSCC cell lines. The data presented in our study clearly demonstrates that the 7 HNSCC cell lines that were characterised in this study are not strictly epithelial and have varying degrees of mesenchymal expression at mRNA, protein and functional levels. The HPV-16 positive cell lines (UD-SCC2, 93-VU147T) and HPV-negative (SCC25, RPMI2650) associated with a mesenchymal genotype. 
Interestingly, CAL27, presented with strong epithelial and mesenchymal expression had the most migratory and invasive properties. SCC25 appeared to be the anomaly where there was strong mesenchymal expression (Vimentin), however the migratory and invasive capabilities were lower than the other cell lines investigated. The metastatic HNSCC cell line RPMI2650 had lower expression of epithelial markers but had strong Vimentin expression. At a functional level, the proliferative rates of the HPV-16 positive cell lines were the slowest, however they were found to be more migratory and invasive than the HNSCC cell line panel.

UD-SCC2, RPMI2650, SCC25 and CAL27 at mRNA and protein expression, present with a more mesenchymal nature than FaDu, SCC15 or 93-VU-147T. However, there was co-expression of the epithelial markers (E-cadherin, EpCAM, cytokeratins) which gives rise to a state of epithelialmesenchymal plasticity (EMP). ${ }^{[9,32]}$ This is a dynamic state where cells gain and maintain both epithelial and mesenchymal cell types. ${ }^{[32,33]}$ When the HPV-16 positive cell lines are compared to each other at a protein level, UD-SCC2 has a more mesenchymal nature to it than 93-VU-147T due to lower expression of E-cadherin and no EpCAM expression and the presence of Vimentin which is frequently used as a marker of EMT. ${ }^{[33]}$

Similar expression levels of E-cadherin and N-cadherin across the 7 cell lines. In RPMI2650, there was a lack of expression of either of these two markers. E-cadherin, a cell surface protein and an epithelial marker, is an important protein of the adherens junctions which anchor oral epithelial cells to each other. E-cadherins are calcium binding transmembrane glycoproteins involved in adhesion between epithelial cells by homophillic interactions. ${ }^{[33]}$ E-cadherin expression has been found to be similarly expressed in primary and metastatic sites and this has been attributed to the reverse of EMT which the cells undergo, a process termed mesenchymal-epithelial transition (MET) at the metastatic sites. ${ }^{[33]}$ Cadherin switching between E-cadherin and Ncadherin (e.g. Low expression of E-cadherin and high expression of $\mathrm{N}$-cadherin) has been observed with an increase in invasion and metastasis. ${ }^{[33,34]} \mathrm{N}$-cadherin is expressed in all the cell lines except for RPMI2650. The expression is similar to that of E-cadherin across the cell lines. N-cadherin plays an important role in the shape organisation of epithelial tissues. They are proteins of the adherins junctions and are expressed predominantly in mesenchymal cells. During EMT, E-cadherin is downregulated and $\mathrm{N}$-cadherin is upregulated. This is characteristic of mesenchymal cells. ${ }^{[35]}$

Epithelial cell adhesion molecule (EpCAM) is expressed across most cell lines except for a reduction in its protein

Published by Sciedu Press expression in SCC25, RPMI2650 and UD-SCC2. However, these are the only three cell lines expressing the mesenchymal marker, Vimentin. EpCAM is involved in cell-cell and cell-matrix adhesion. Lower EpCAM expression has been observed in the metastatic sites when compared to the primary tumours. ${ }^{[36]}$ This can be attributed to the loss of cellular adhesion as a result of EMT which leads to metastasis. During EMT, EpCAM is downregulated showing co-expression of N-cadherin and Vimentin and in doing so can eventually disappear. ${ }^{[35]}$ This is representative in SCC25, RPMI2650 and UD-SCC2.

HPV-16 positive cell line, UD-SCC2 expresses vimentin at the mRNA and protein levels. SCC25 interestingly has strong expression of Vimentin at both a gene and protein level, consistent with the human fibroblast cell line which shows similar associations with gene expression. RPMI2650 as expected demonstrated vimentin expression, highlighting the mesenchymal nature in this cell line. Vimentin, an intermediate filament is a marker of mesenchymal cells. Vimentin has been found to be expressed at sites where a more migratory and invasive phenotype is observed and its expression induces a mesenchymal morphology of cells and an increase in mobility. ${ }^{[35,37]}$ An increase in Vimentin expression is typically used as a marker of EMT in carcinogenesis and has been found to be highly expressed in nodal metastatic sites when compared to primary sites. ${ }^{[37]}$ Vimentin expression has found to be induced by transforming growth factor- $\beta$ (TGF- $\beta$ ) and epidermal growth factor (EGF). Moreover, RNA interference mediated knockdown of Vimentin has shown a decrease in proliferative, migratory and invasive rates of cells through the basement membrane into the lymphovasculature, thereby reducing the tumorigenic potential. ${ }^{[18]}$

The lack of EGFR expression for the metastatic HNSCC cell line, RPMI2650 was present at both gene and protein level. This is observed in the lack of EGFR staining in the cell spin (see Figure 5A). EGFR has been well studied as a prognostic biomarker and therapeutic target in HNSCC. EGFR is a transmembrane tyrosine kinase receptor that has been found to be overexpressed in more than $90 \%$ of HNSCC. EGFR ligand binding causes homo/hetero-dimerization with other members of the EGF family which results in the autophosphorylation and activation of downstream signalling pathways such as the P13K/Akt, Ras/RAF/MEK/ERK1/2 and STAT pathways. Alterations in these signalling pathways can lead to the progression of cancer by uncontrolled cell proliferation. ${ }^{[38]}$ In Summary, the current study presents the molecular and phenotypic diversity in both HPV-16 negative and HPV-16 positive cell lines, in particular UD-SCC2, presents with a more mesenchymal cell type. It underpins the need for additional studies and a scoring system where 
HNSCC cell lines are ranked according to their respective epithelial and mesenchymal nature which in turn could inform treatment.

\section{ACKNOWLEDGements}

The authors would like to thank Dr Johan de Winter (VU Medical Centre Amsterdam, Netherlands) for the cell line 93VU-147T as well as Dr Thomas Hoffman (Uniklinik) for the cell line UD-SCC2. Furthermore, A/Prof Nick Saunders for SCC15 and SCC25. Dr Brett Hollier and Nataly Stylianou for the primers and antibodies. Dr Varinder Jeet for Incuctye assistance. Mr Tony Blick for gene expression assistance. Moreover, Prof Rik Thompson, Dr Andrew J Dalley and Dr
Ryan Chai for editorial work.

This study was supported by the Queensland Centre for Head and Neck Cancer funded by Atlantic Philanthropies, the Queensland Government, and the Princess Alexandra Hospital. In addition, we acknowledge the financial support from the Queensland University of Technology VC's start-up funds for C.P.

\section{CONFlicts OF INTEREST Disclosure}

Dr. Anthony M Davies is the inventor of the Happy Cell media and is also a major shareholder and a director of the company that currently commercializes this technology. For all other authors, no competing financial interests exist.

\section{REFERENCES}

[1] Howlader N NA, Krapcho M, Garshell J, et al. SEER Cancer Statistics Review, 1975-2010. National Cancer Institute. 2012 [updated 2013]. Available from: http://seer.cancer.gov/csr/1975_2 010/.

[2] Jimenez L, Jayakar SK, Ow TJ, et al. Mechanisms of Invasion in Head and Neck Cancer. Archives of pathology \& laboratory medicine. 2015 Jun 5. http: //dx.doi .org/10.5858/arpa. 2014-0498-R A

[3] van Imhoff LC, Kranenburg GG, Macco S, et al. The prognostic value of continued smoking on survival and recurrence rates in head and neck cancer patients: A systematic review. Head \& neck. 2015 Apr 20. PMid:25900211. http://dx.doi.org/10.1002/hed. 24082

[4] Kulasinghe A, Perry C, Jovanovic L, et al. Circulating Tumour Cells in Metastatic Head and Neck Cancers. International journal of cancer. 2014 Aug 1. PMid:25111594.

[5] Umbreit C, Flanjak J, Weiss C, et al. Incomplete EpithelialMesenchymal Transition in p16-positive Squamous Cell Carcinoma Cells Correlates with beta-Catenin Expression. Anticancer research. 2014 Dec; 34(12): 7061-9. PMid:25503133.

[6] Chai RC, Lambie D, Verma M, et al. Current trends in the etiology and diagnosis of HPV-related head and neck cancers. Cancer Med. 2015 Apr; 4(4): 596-607. PMid:25644715. http://dx.doi.org $/ 10.1002 /$ cam 4.424

[7] Salazar C, Calvopina D, Punyadeera C. miRNAs in human papilloma virus associated oral and oropharyngeal squamous cell carcinomas. Expert review of molecular diagnostics. 2014 Nov; 14(8): 103340. PMid:25222489. http://dx.doi.org/10.1586/14737159. 2014.960519

[8] Kulasinghe A LY, Perry C, Punyadeera C. Current Trends and Management in Head and Neck Cancer. In: Hall MR, editor. Head and Neck Cancer: Epidemiology, Management and Treatment Outcomes. Cancer Etiology, Diagnosis and Treatments: Nova Science Publishers; 2015: 41-74.

[9] Klijn C, Durinck S, Stawiski EW, et al. A comprehensive transcriptional portrait of human cancer cell lines. Nature biotechnology. 2015 Mar; 33(3): 306-12. PMid:25485619. http://dx.doi .org/10.10 $38 / \mathrm{nbt} .3080$

[10] The Cancer Genome Atlas N. Comprehensive genomic characterization of head and neck squamous cell carcinomas. Nature. 2015 01/29/print; 517(7536): 576-82.
[11] van Denderen BJ, Thompson EW. Cancer: The to and fro of tumour spread. Nature. 2013 Jan 24; 493(7433): 487-8. PMid:23344357. http://dx.doi.org/10.1038/493487a

[12] Tomaskovic-Crook E, Thompson EW, Thiery JP. Epithelial to mesenchymal transition and breast cancer. Breast cancer research: BCR 2009; 11(6): 213. PMid:19909494. http://dx.doi.org/10.11 $86 /$ bcr 2416

[13] Graves CA, Abboodi FF, Tomar S, et al. The translational significance of epithelial-mesenchymal transition in head and neck cancer. Clinical and translational medicine. 2014 Dec; 3(1): 60. PMid:25632320. http://dx.doi .org/10.1186/s40169-014-0039-9

[14] Chaw SY, Abdul MA, Dalley AJ, et al. Epithelial to mesenchymal transition (EMT) biomarkers - E-cadherin, beta-catenin, APC and Vimentin - in oral squamous cell carcinogenesis and transformation. Oral Oncol. 2012 Oct; 48(10): 997-1006. PMid:22704062. http: //dx.doi.org/10.1016/j.oraloncology.2012.05.011

[15] Biddle A, Liang X, Gammon L, et al. Cancer stem cells in squamous cell carcinoma switch between two distinct phenotypes that are preferentially migratory or proliferative. Cancer research. 2011 Aug 1; 71(15): 5317-26. PMid:21685475. http://dx.doi.org/10.1158 10008-5472. CAN-11-1059

[16] Nguyen PT, Kudo Y, Yoshida M, et al. N-cadherin expression is involved in malignant behavior of head and neck cancer in relation to epithelial-mesenchymal transition. Histology and histopathology. 2011 Feb; 26(2): 147-56. PMid:21154228.

[17] Chang HW, Roh JL, Jeong EJ, et al. Wnt signaling controls radiosensitivity via cyclooxygenase-2-mediated Ku expression in head and neck cancer. International journal of cancer. 2008 Jan 1; 122(1): 1007. PMid:17764107. http://dx.doi.org/10.1002/ijc. 23069

[18] Paccione RJ, Miyazaki H, Patel V, et al. Keratin down-regulation in vimentin-positive cancer cells is reversible by vimentin RNA interference, which inhibits growth and motility. Molecular cancer therapeutics. 2008 Sep; 7(9): 2894-903. PMid:18790770. http: //dx.doi.org/10.1158/1535-7163.MCT-08-0450

[19] Dooley TP, Reddy SP, Wilborn TW, et al. Biomarkers of human cutaneous squamous cell carcinoma from tissues and cell lines identified by DNA microarrays and qRT-PCR. Biochemical and biophysical research communications. 2003 Jul 11; 306(4): 1026-36. http://dx.doi .org/10.1016/S0006-291X (03) 01099-4

[20] Warawdekar UM, Zingde SM, Iyer KS, et al. Elevated levels and fragmented nature of cellular fibronectin in the plasma of gastrointestinal 
and head and neck cancer patients. Clinica chimica acta; international journal of clinical chemistry. 2006 Oct; 372(1-2): 83-93.

[21] Lyons JG, Patel V, Roue NC, et al. Snail up-regulates proinflammatory mediators and inhibits differentiation in oral keratinocytes. Cancer research. 2008 Jun 15; 68(12): 4525-30. PMid:18559496. http://dx.doi.org/10.1158/1078-0432.CCR-07-6735

[22] Hsu DS, Lan HY, Huang CH, et al. Regulation of excision repair cross-complementation group 1 by Snail contributes to cisplatin resistance in head and neck cancer. Clinical cancer research: an official journal of the American Association for Cancer Research. 2010 Sep 15; 16(18): 4561-71.

[23] Mani SA, Guo W, Liao MJ, et al. The Epithelial-Mesenchymal Transition Generates Cells with Properties of Stem Cells. Cell. 2008; 133(4): 704-15. PMid:18485877. http://dx.doi.org/10.1016 /j.cell.2008.03.027

[24] AbdulMajeed AA, Dalley AJ, Farah CS. Putative cancer stem cell marker expression in oral epithelial dysplasia and squamous cell carcinoma. Journal of Oral Pathology \& Medicine. 2013; 42(10): 755-60. PMid:23614644. http://dx.doi.org/10.1111/jop.12073

[25] Zhang Q, Shi S, Yen Y, et al. A subpopulation of CD133+ cancer stem-like cells characterized in human oral squamous cell carcinoma confer resistance to chemotherapy. Cancer Letters. 2010; 289(2): 151-60. PMid:19748175. http://dx.doi.org/10.1016/j.can let.2009.08.010

[26] Dalley AJ, Pitty LP, Major AG, et al. Expression of ABCG2 and Bmi-1 in oral potentially malignant lesions and oral squamous cell carcinoma. Cancer medicine. 2014 Apr; 3(2): 273-83.

[27] Prince ME, Sivanandan R, Kaczorowski A, et al. Identification of a subpopulation of cells with cancer stem cell properties in head and neck squamous cell carcinoma. Proc Natl Acad Sci USA. 2007 Jan 16; 104(3): 973-8. PMid:17210912.http://dx.doi.org/10.10 73/pnas.0610117104

[28] Chen TR. In situ detection of mycoplasma contamination in cell cultures by fluorescent Hoechst 33258 stain. Experimental cell research. 1977 Feb; 104(2): 255-62. http://dx.doi .org/10.1016 10014-4827 (77) 90089-1

[29] Pandit P, Cooper-White J, Punyadeera C. High-yield RNA-extraction method for saliva. Clinical chemistry. 2013 Jul; 59(7): 1118-
22. PMid:23564756. http://dx.doi.org/10.1373/clinchem. 2012. 197863

[30] Kulasinghe A, Perry C, Jovanovic L, et al. A liquid Biopsy for head and neck cancers. Expert Reviews in Molecular Diagnostics. 2015 Dec 3 [Epub ahead of print]. PMid: 26631411.

[31] Attramadal CG, Kumar S, Boysen ME, et al. Tumor Budding, EMT and Cancer Stem Cells in T1-2/N0 Oral Squamous Cell Carcinomas. Anticancer research. 2015 Nov; 35(11): 6111-20. PMid:26504037.

[32] Pinto CA, Widodo E, Waltham M, et al. Breast cancer stem cells and epithelial mesenchymal plasticity - Implications for chemoresistance. Cancer Lett. 2013 Nov 28; 341(1): 56-62. PMid:23830804. http://dx.doi.org/10.1016/j.canlet.2013.06.003

[33] Scanlon CS, Van Tubergen EA, Inglehart RC, et al. Biomarkers of Epithelial-Mesenchymal Transition in Squamous Cell Carcinoma. Journal of dental research. 2013; 92(2): 114-21. PMid:23128109. http://dx.doi.org/10.1177/0022034512467352

[34] Yang MH, Chang SY, Chiou SH, et al. Overexpression of NBS1 induces epithelial-mesenchymal transition and co-expression of NBS1 and Snail predicts metastasis of head and neck cancer. Oncogene. 2007; 26(10): 1459-67. PMid:16936774. http://dx.doi .org/10. 1038/sj . onc. 1209929

[35] Barriere G, Fici P, Gallerani G, et al. Circulating tumor cells and epithelial, mesenchymal and stemness markers: characterization of cell subpopulations. Annals of translational medicine. 2014; 2(11): 109. PMid:25489583.

[36] Takes RP, Baatenburg de Jong RJ, Wijffels K, et al. Expression of genetic markers in lymph node metastases compared with their primary tumours in head and neck cancer. The Journal of pathology. 2001; 194(3): 298-302. http://dx.doi.org/10.1002/1096-9 896 (200107) 194: 3<298: :AID-PATH900>3.0.CO; 2-Q

[37] Zeisberg M, Neilson EG. Biomarkers for epithelial-mesenchymal transitions. The Journal of clinical investigation. 2009 Jun; 119(6): 1429-37. PMid:19487819. http://dx.doi .org/10.1172/JCI36 183

[38] Sahu N, Grandis JR. New advances in molecular approaches to head and neck squamous cell carcinoma. Anti-cancer drugs. 2011 Aug; 22(7): 656-64. PMid:21178766. http://dx.doi.org/10.1097/C AD. 0b013e32834249ba 